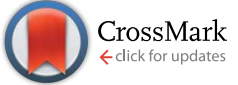

Cite this: Chem. Sci., 2015, 6, 301

\section{Core-shell structured phosphorescent nanoparticles for detection of exogenous and endogenous hypochlorite in live cells via ratiometric imaging and photoluminescence lifetime imaging microscopy $\dagger$}

\author{
Kenneth Yin Zhang,,$^{a}$ Jie Zhang, $\dot{t}^{a}$ Yahong Liu, ${ }^{a}$ Shujuan Liu, ${ }^{a}$ Pinglin Zhang, ${ }^{a}$ \\ Qiang Zhao, ${ }^{* a}$ Yan Tang ${ }^{a}$ and Wei Huang*ab
}

\begin{abstract}
We report a ratiometric phosphorescence sensory system for hypochlorite $\left(\mathrm{ClO}^{-}\right)$based on core-shell structured silica nanoparticles. Two phosphorescent iridium(III) complexes were immobilised in the inner solid core and outer mesoporous layer of the nanoparticles, respectively. The former is insensitive to $\mathrm{ClO}^{-}$and thus serves as an internal standard to increase the accuracy and precision, while the latter exhibits a specific and significant luminogenic response to $\mathrm{ClO}^{-}$, providing high selectivity and sensitivity. Upon exposure to $\mathrm{ClO}^{-}$, the nanoparticles display a sharp luminescence colour change from blue to red. Additionally, intracellular detection of exogenous and endogenous $\mathrm{ClO}^{-}$has been demonstrated via ratiometric imaging and photoluminescence lifetime imaging microscopy. Compared to intensity-based sensing, ratiometric and lifetime-based measurements are independent of the probe concentration and are thus less affected by external influences, especially in intracellular applications.
\end{abstract}

Received 26th August 2014 Accepted 22nd September 2014

DOI: $10.1039 / \mathrm{c} 4 \mathrm{sc0} 02600 \mathrm{~d}$

www.rsc.org/chemicalscience

\section{Introduction}

Hypochlorite $\left(\mathrm{ClO}^{-}\right)$is an oxidizing agent that has been widely applied for bleaching, disinfection, and water treatment. ${ }^{1}$ In biology, $\mathrm{ClO}^{-}$, as one of the important reactive oxygen species (ROS), plays an important role in the destruction of pathogens in the immune system. ${ }^{2}$ It is produced endogenously in leukocytes by myeloperoxidase (MPO) which catalyzes the oxidation of chloride to $\mathrm{ClO}^{-}$by hydrogen peroxide. ${ }^{3}$ Unregulated $\mathrm{ClO}^{-}$ production may be associated with various cardiovascular diseases, neuron degeneration, arthritis and cancer. ${ }^{4}$ Owing to the important biological roles of $\mathrm{ClO}^{-}$, the design of sensitive and selective probes for its accurate and precise detection has attracted much attention. Optical probes including organic dyes, ${ }^{5}$ nanoparticles, ${ }^{6}$ transition metal complexes ${ }^{7}$ and lanthanide chelates ${ }^{8}$ are the most frequently used reagents to detect intracellular $\mathrm{ClO}^{-}$. Most of these probes exhibit emission

${ }^{a}$ Key Laboratory for Organic Electronics \& Information Displays and Institute of Advanced Materials, Nanjing University of Posts and Telecommunications, Nanjing 210023, P.R. China. E-mail: iamqzhao@njupt.edu.cn; wei-huang@njtech.edu.cn; Fax: +86 25-85866396

${ }^{b}$ Institute of Advanced Materials, Jiangsu-Singapore Joint Research Centre for Organic/ Bio-Electronics \& Information Displays, Nanjing Tech University, Nanjing 211816, P.R. China

$\dagger$ Electronic supplementary information (ESI) available: Experimental procedures, characterisation data, Scheme S1 and Fig. S1-S3. See DOI: 10.1039/c4sc02600d

\$ K. Y. Zhang and J. Zhang contributed equally to this work. enhancement upon oxidation by $\mathrm{ClO}^{-}$and offer high sensitivity and excellent spatial and temporal resolution in intracellular and in vivo detection via luminescence imaging techniques..$^{5,6,7 b, 8}$

In addition to intensity-based probes, wavelength-ratiometric probes have received much interest. ${ }^{5 i, 9}$ The presence of analyte can be reflected by a change in the ratio of intensities at two luminescence wavelengths. Ratiometric probes are self-calibrating and have high accuracy and precision, especially in intracellular and in vivo detection. However, the use of ratiometric probes is relatively rare compared to intensity-based sensors because of the difficulty in the design and synthesis of ratiometric dyes. Here, we describe a general approach for the convenient preparation of luminescent ratiometric probes. Core-shell structured silica nanoparticles are selected to construct ratiometric probes because these particles exhibit excellent hydrophilicity, biocompatibility and stability. ${ }^{\mathbf{1 0}}$ Importantly, the core and shell allow independent modification to meet their respective requirements. As shown in Fig. 1, the solid core is covalently labelled with an emissive reference compound that is insensitive to the analyte and thus can serve as an internal standard to increase the accuracy and precision of the measurement, while mesoporous silica is employed to form the outer shell in which a regular arrangement of mesopores facilitates fast and efficient adsorption of a responsive compound that shows a specific and significant luminogenic response to the 


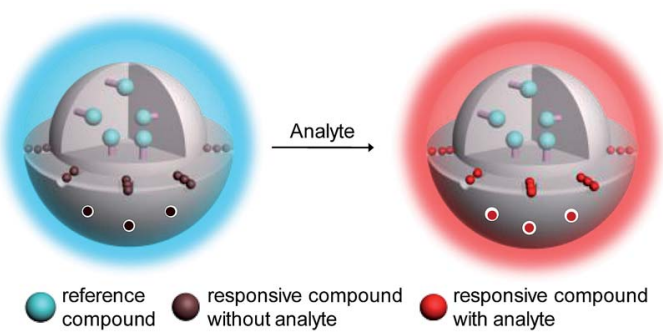

Fig. 1 Design concept of a ratiometric probe based on core-shell structured nanoparticles.

analyte, providing high selectivity and sensitivity. Upon interaction with the analyte, these nanoparticles will display changes in their luminescence profile, from dominance of the reference compound to dominance of the responsive one (Fig. 1).

Lifetime-based measurements are another powerful method to identify the presence of analyte when a probe exhibits changes in emission lifetime upon interaction with the analyte. The fast development of photoluminescence lifetime imaging microscopy (PLIM) facilitates the lifetime-based detection of intracellular analytes. Similar to the intensity ratio of a ratiometric probe, the lifetime of a probe is independent of the probe concentration or the power of the laser source. Phosphorescent transition metal complexes have been attracting much interest in intracellular sensing owing to their interesting phosphorescence characteristics such as high photostabilities, high phosphorescence quantum yields, large Stokes shifts and tunable phosphorescence colours. ${ }^{11}$ Additionally, their long and sensitive phosphorescence lifetimes allow lifetime-based measurements in the absence of interference from short-lived scattering and autofluorescence. ${ }^{12}$

In this work, two phosphorescent iridium(III) complexes $\mathbf{1}$ and 2 (Scheme 1) have been prepared to serve as $\mathrm{ClO}^{-}$insensitive and sensitive compounds, respectively, to construct the core-shell structured ratiometric sensor $\mathrm{SiO}_{2}-\mathbf{1} @ \mathrm{mSiO}_{2}-2$. Utilisation of $\mathrm{SiO}_{2}-1 @ \mathrm{mSiO}_{2}-2$ to detect intracellular exogenous and endogenous $\mathrm{ClO}^{-}$has been demonstrated via ratiometric imaging and PLIM.

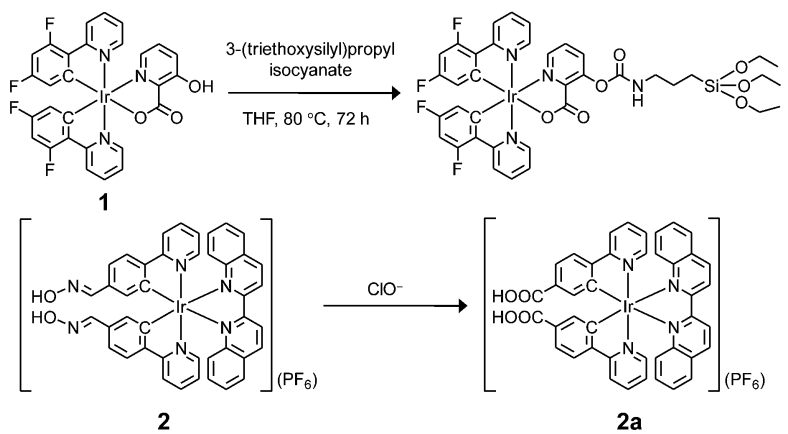

Scheme 1 Preparation of iridium(III) silane analogue from complex 1 and recognition mechanism of complex 2 toward $\mathrm{ClO}^{-}$.

\section{Results and discussion}

\section{Design and properties of the reference and responsive iridium(III) complexes}

Complex 1 was prepared as the reference compound as it is unreactive toward $\mathrm{ClO}^{-}$and the hydroxyl group allows covalent immobilisation onto silica particles (Scheme 1). Complex 2 was designed as the responsive compound because it shows a phosphorogenic response toward $\mathrm{ClO}^{-}$due to elimination of the isomerisation of the aldoxime groups $(\mathrm{C}=\mathrm{N}-\mathrm{OH}){ }^{5 \boldsymbol{d}, 7 \boldsymbol{7}, \boldsymbol{c}}$ The selection of 2,2'-biquinoline as the diimine ligand was to tune the emission colour of complex 2 into the red region, and thus the emission spectrum was separated from that of the blueemissive complex 1. Complex 2 was obtained from reaction of the bis(pyridylbenzaldehyde) analogue with hydroxylamine hydrochloride in refluxing methanol/dichloromethane (Scheme $\mathrm{S} 1 \dagger)$. The complexes were characterized by ${ }^{1} \mathrm{H}$ NMR spectroscopy, IR spectroscopy and positive-ion MALDI-TOF-MS (ESI $\dagger$ ).

Upon photoexcitation, complex 1 displayed a structured emission band with the maxima at 479 and $500 \mathrm{~nm}$, while complex 2 showed a broad band centred at $609 \mathrm{~nm}$ (Fig. 2a). The emissions of complexes $\mathbf{1}$ and $\mathbf{2}$ have been assigned to triplet intraligand $\left({ }^{3} \mathrm{IL}\right)$ and metal-to-ligand charge-transfer $\left({ }^{3} \mathrm{MLCT}\right)$ excited states, respectively. It is noteworthy that complexes $\mathbf{1}$ and 2 could be simultaneously excited at $405 \mathrm{~nm}$, which is one of the most commonly used laser sources in confocal microscopy, and that their respective blue and red phosphorescences were spectrally well separated $(\Delta \lambda>100 \mathrm{~nm})$. Additionally, both complexes retained their phosphorescence intensities when
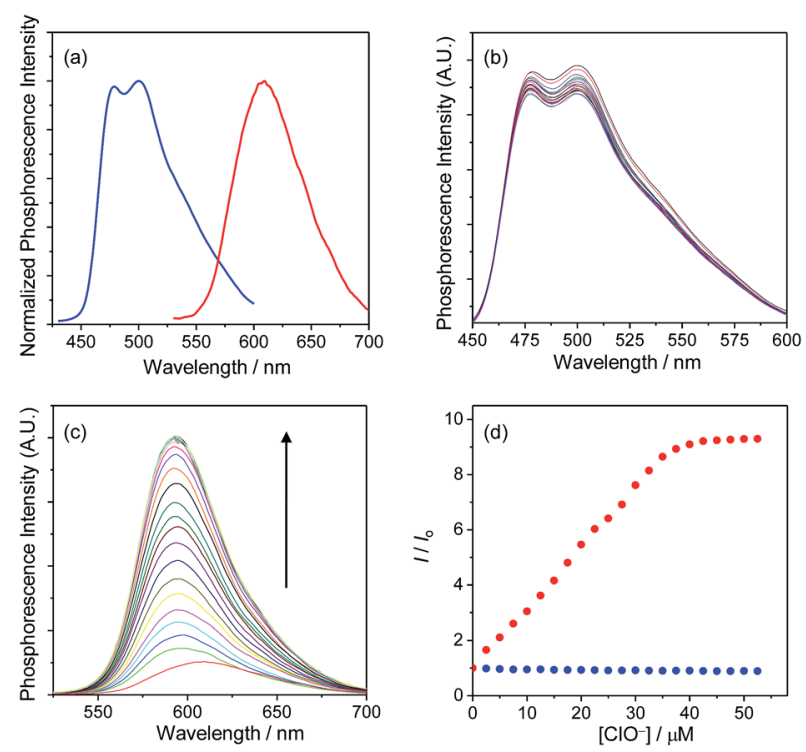

Fig. 2 (a) Normalized phosphorescence spectra of complexes 1 (blue) and 2 (red) in $\mathrm{MeOH}$ at $298 \mathrm{~K}$. (b) Phosphorescence spectral traces of complex $1(1.4 \mu \mathrm{M})$ in $\mathrm{MeOH}$ at $298 \mathrm{~K}$ in the presence of $0-50 \mu \mathrm{M}$ $\mathrm{NaClO}$. (c) Phosphorescence spectral traces of complex $2(1.5 \mu \mathrm{M})$ in $\mathrm{MeOH}$ at $298 \mathrm{~K}$ in the presence of $0-50 \mu \mathrm{M} \mathrm{NaClO}$. (d) Phosphorescence titration curves of complexes 1 (blue) and 2 (red). The excitation wavelength was $405 \mathrm{~nm}$. The emission intensities of complexes 1 and 2 were monitored at 500 and $598 \mathrm{~nm}$, respectively. 
mixed with each other, indicating limited energy or electron transfer between these two complexes.

The phosphorescence responses of complexes 1 and 2 toward $\mathrm{ClO}^{-}$were studied via emission titrations in $\mathrm{MeOH}$ due to their limited water solubility. Results showed that addition of $\mathrm{ClO}^{-}$to complex 1 did not cause any notable change in the phosphorescence spectrum or lifetime (about 69 and $72 \mathrm{~ns}$ in the absence and presence of $\mathrm{ClO}^{-}$, respectively), whereas complex 2 displayed a phosphorescence enhancement of about 9.2 fold at $598 \mathrm{~nm}$ and lifetime elongation from 265 to $410 \mathrm{~ns}$ upon addition of $\mathrm{ClO}^{-}$(Fig. 2b-d). The significant phosphorescence change of complex 2 has been ascribed to the formation of the bis-carboxyl analogue 2a upon oxidation by $\mathrm{ClO}^{-}$ (Scheme 1), eliminating the isomerisation of the aldoxime groups ${ }^{5 d, 7 a, c}$ which is an effective nonradiative decay process and quenches the phosphorescence of complex 2. The generation of complex $2 \mathbf{a}$ has also been confirmed by the positive-ion MALDI-TOF mass spectrometry, which revealed a peak at $\mathrm{m} / \mathrm{z}=$ 845 , corresponding to the bis-carboxyl complex 2a cation. All these photophysical properties of complexes $\mathbf{1}$ and $\mathbf{2}$ and their sensory behaviours fulfilled the requirements of cooperation in a hybridised ratiometric sensory system.

\section{Preparation of core-shell structured nanoparticles}

In the preparation of core-shell structured nanoparticles, ${ }^{13}$ complex 1 first reacted with 3-(triethoxysilyl)propyl isocyanate to give the iridium(III) silane analogue (Scheme 1), which was then used to prepare the solid silica core with tetraethyl orthosilicate (TEOS) as a crosslinking reagent. After that, the core was coated with a mesoporous silica layer in the presence of TEOS and surfactant cetyltrimethylammonium bromide (CTAB). Incubation of these nanoparticles with complex $2(1 \mathrm{mg}$ $\mathrm{ml}^{-1}$ ) in ethanol allows efficient adsorption, giving the target ratiometric probe $\mathrm{SiO}_{2}-1 @ \mathrm{mSiO}_{2}-2$. The transmission electron microscopy (TEM) images showed that the nanoparticles were well dispersed in solution and spherical in shape with a core diameter of about $80 \mathrm{~nm}$ and a shell thickness of $18 \mathrm{~nm}$ (Fig. 3a), which was consistent with the dynamic light scattering (DLS) measurements which revealed an average diameter of 123 $\mathrm{nm}$ for $\mathrm{SiO}_{2}-1 @ \mathrm{mSiO}_{2}-2$ dispersed in PBS solution. The smallangle X-ray diffraction (XRD) patterns indicated a typical hexagonally packed mesoporous structure (Fig. 3b). The nitrogen adsorption/desorption isotherm measurements for the $\mathrm{SiO}_{2}-\mathbf{1} @ \mathrm{mSiO}_{2}-\mathbf{2}$ nanoparticles (Fig. 3c) revealed a surface area of $710.9 \mathrm{~m}^{2} \mathrm{~g}^{-1}$, and a well-defined Barrett-Joyner-Halenda (BJH) pore size of about $3.1 \mathrm{~nm}$ was observed (Fig. 3d). The Fourier transform infrared (FTIR) spectrum indicated that complex 1 was covalently immobilised through a carbamate linker (Fig. S1 $\dagger$ ). The zeta potentials of the nanoparticles changed from -32 to $+42 \mathrm{mV}$ upon adsorption of the cationic complex 2. The loading amounts of complexes 1 and 2 were calculated to be about 1.0 and $1.5 \mu \mathrm{g}$ per $1 \mathrm{mg}$ of nanoparticles, respectively, based on their absorption spectra (Fig. S2 $\dagger$ ). Additionally, the absorption spectrum of $\mathrm{SiO}_{2}-1 @ \mathrm{mSiO}_{2}-2$ in $\mathrm{H}_{2} \mathrm{O}$ did not show any remarkable change when the solution (a)
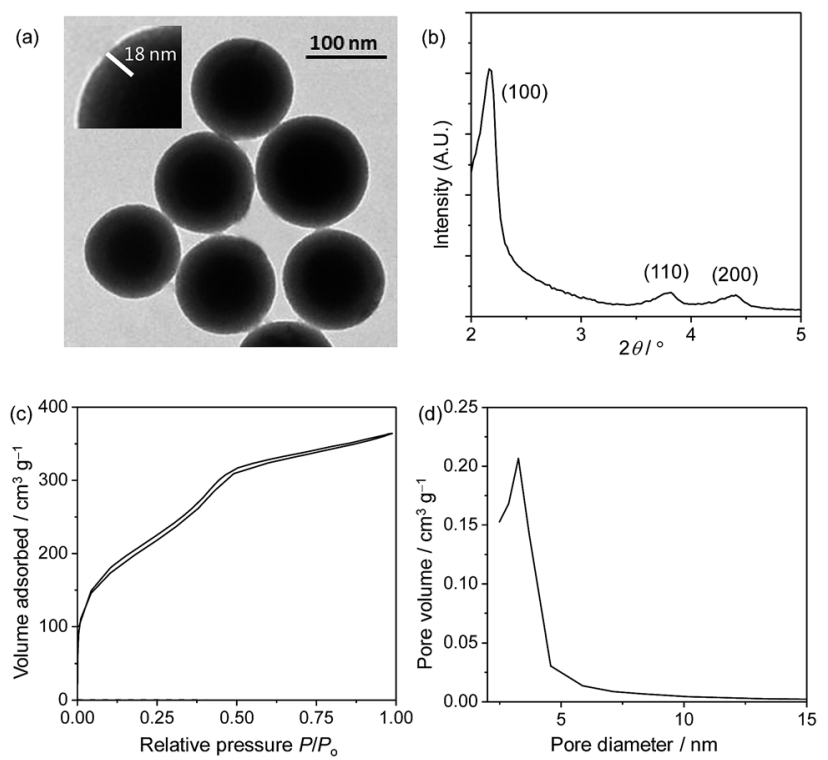

Fig. 3 TEM image (a), XRD pattern (b), nitrogen adsorption/desorption isotherms (c) and pore diameter distribution (d) of $\mathrm{SiO}_{2}-1 \mathrm{amSiO}_{2}-2$.

was left to stand for more than four weeks, indicative of the high stability of the nanoparticles.

\section{Phosphorescence response to $\mathrm{ClO}^{-}$}

The phosphorescence response of the core-shell structured nanoparticles $\mathrm{SiO}_{2}-\mathbf{1} @ \mathrm{mSiO}_{2}-2$ to $\mathrm{ClO}^{-}$was investigated in phosphate buffered saline (PBS, $\mathrm{pH}=7.4$ ) solution owing to the good solubility of $\mathrm{SiO}_{2}-1 @ \mathrm{mSiO}_{2}-2$ in aqueous solutions. In the absence of $\mathrm{ClO}^{-}, \mathrm{SiO}_{2}-1 @ \mathrm{mSiO}_{2}-2$ retained the phosphorescence of both complexes 1 and 2 and displayed intense blue phosphorescence ( $\tau=83 \mathrm{~ns}$ ) with a weak emission shoulder in the red region ( $\tau=171 \mathrm{~ns})$. Additionally, the emission spectrum of $\mathrm{SiO}_{2}-1 @ \mathrm{mSiO}_{2}-2$ is quite similar to that of the mixture containing $\mathrm{SiO}_{2}-1 @ \mathrm{mSiO}_{2}$ and complex 2, suggestive of negligible energy transfer or emission-reabsorption. Compared to the lifetimes of complexes $1(\tau=69 \mathrm{~ns})$ and $2(\tau=265 \mathrm{~ns})$ in $\mathrm{MeOH}$, the blue phosphorescence showed a similar lifetime in PBS solution, while the decay of the red phosphorescence was much faster. This is in accordance with the fact that an MLCT emitter displays a shorter lifetime in a more polar solvent, while the lifetime of an IL emitter is less affected by the polarity of solvents. ${ }^{14}$ It may also be associated with the fact that complex 1 is protected by the inner solid core, while complex 2 is just adsorbed on the outer layer of the nanoparticles. Upon addition of $\mathrm{ClO}^{-}$, the intensity of the red phosphorescence was increased by 5.8 fold with a lifetime elongation to $406 \mathrm{~ns}$, whereas the blue phosphorescence did not show any remarkable difference in either intensity or lifetime ( $\tau=82 \mathrm{~ns}$ ) (Fig. 4a). These results are in line with the phosphorescence responses of complexes $\mathbf{1}$ and 2 toward $\mathrm{ClO}^{-}$(Fig. 2b-d). $\mathrm{SiO}_{2}-1 @ \mathrm{mSiO}_{2}-2$ showed a smaller enhancement factor of the red phosphorescence compared to the response of complex 2 to $\mathrm{ClO}^{-}$, which is due to steric hindrance caused by the silica particles, limiting the full 

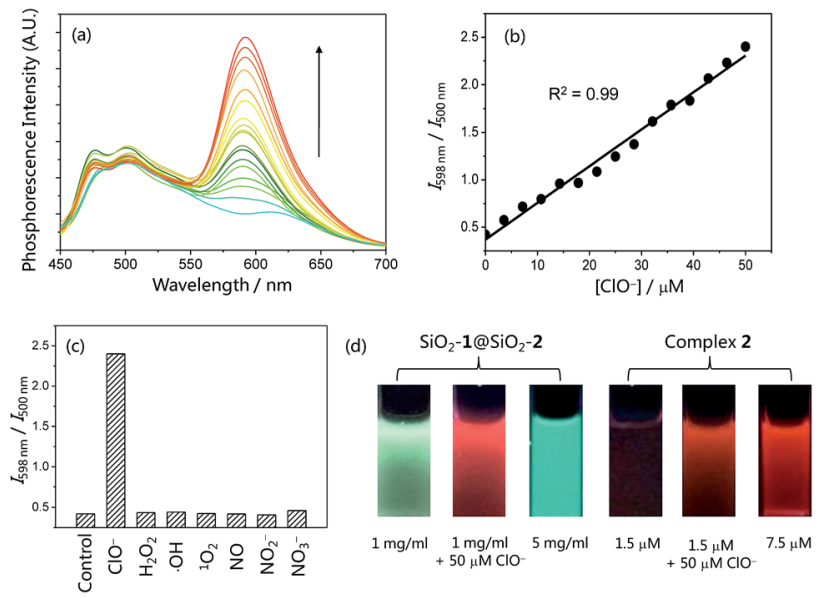

Fig. 4 (a) Phosphorescence spectral traces of $\mathrm{SiO}_{2}-1 \mathrm{amSiO}_{2}-2$ $\left(1 \mathrm{mg} \mathrm{ml}^{-1}\right)$ in PBS buffer $(\mathrm{pH}=7.4)$ at $298 \mathrm{~K}$ in the presence of 0 $50 \mu \mathrm{M} \mathrm{NaClO}$. (b) Plots of $/ 598 \mathrm{~nm} / 500 \mathrm{~nm}$ as a function of $\mathrm{ClO}^{-}$ concentration. (c) Selective ratiometric response of $\mathrm{SiO}_{2}-1 \mathrm{amSiO}_{2}-2$ $\left(1 \mathrm{mg} \mathrm{ml}^{-1}\right)$ toward $\mathrm{ClO}^{-}(50 \mu \mathrm{M})$ over other ROS and RNS $(200 \mu \mathrm{M})$ in PBS buffer at $298 \mathrm{~K}$. (d) Photographs of $\mathrm{SiO}_{2}-1 \mathrm{amSiO}_{2}-2$ in PBS solution and complex 2 in $\mathrm{MeOH}$ under excitation at $365 \mathrm{~nm}$.

interaction between complex 2 and $\mathrm{ClO}^{-}$. The intensity ratio of the red phosphorescence over the blue one was enhanced from 0.42 to 2.40 when the concentration of $\mathrm{ClO}^{-}$was increased from 0 to $50 \mu \mathrm{M}$, and a good linearity was obtained (Fig. $4 \mathrm{~b}$ ). The ratiometric response was specific toward $\mathrm{ClO}^{-}$over other ROS and reactive nitrogen species (RNS) including $\mathrm{H}_{2} \mathrm{O}_{2},{ }^{\circ} \mathrm{OH},{ }^{1} \mathrm{O}_{2}$, $\mathrm{NO}, \mathrm{NO}_{2}{ }^{-}$, and $\mathrm{NO}_{3}{ }^{-}$(Fig. 4c). Fig. 4d illustrates the resistance of ratiometric sensing to probe concentration. Addition of $\mathrm{ClO}^{-}$ to $\mathrm{SiO}_{2}-1 @ \mathrm{mSiO}_{2}-2$ resulted in a change in the phosphorescence colour from blue to red. The red phosphorescence of $\mathrm{SiO}_{2}-$ 1@ $\mathrm{mSiO}_{2}-2$ in the presence of $\mathrm{ClO}^{-}$was also in sharp contrast to the blue emission of a concentrated $\mathrm{SiO}_{2}-\mathbf{1} @ \mathrm{mSiO}_{2}-\mathbf{2}$ solution (Fig. $4 \mathrm{~d}$ left). However, it was very difficult to distinguish whether the luminogenic probe complex 2 reacted with $\mathrm{ClO}^{-}$or was just at a high concentration (Fig. $4 \mathrm{~d}$ right), even though it displayed a larger phosphorescence enhancement factor $(9.2$ fold) compared to $\mathrm{SiO}_{2}-\mathbf{1} @ \mathrm{mSiO}_{2}-2$ (5.8 fold). These results suggested that ratiometric probes are more suitable in intracellular and in vivo applications where the concentrations of the probes are difficult to measure or control.

\section{Ratiometric imaging of intracellular $\mathrm{ClO}^{-}$}

Before investigating the intracellular sensing behaviour of $\mathrm{SiO}_{2}-$ $1 @ \mathrm{mSiO}_{2}-2$ toward $\mathrm{ClO}^{-}$, the cytotoxicity of the nanoparticles toward RAW 264.7 cells was evaluated by the 3-(4,5-dimethyl-2thiazolyl)-2,5-diphenyltetrazolium bromide (MTT) assay. ${ }^{15}$ At doses in the range $10-300 \mu \mathrm{g} \mathrm{ml}^{-1}$, cell viability was greater than $95 \%$ after $12 \mathrm{~h}$ of incubation (Fig. 5), indicating the good biocompatibility of $\mathrm{SiO}_{2}-\mathbf{1} @ \mathrm{mSiO}_{2}-\mathbf{2}$. The use of $\mathrm{SiO}_{2}-\mathbf{1} @ \mathrm{mSiO}_{2}-$ 2 to visualise intracellular $\mathrm{ClO}^{-}$was demonstrated via confocal laser-scanning microscopy. The excitation wavelength was $405 \mathrm{~nm}$ and phosphorescence signals in the blue $(480 \pm 20 \mathrm{~nm})$ and red $(600 \pm 20 \mathrm{~nm})$ windows were collected. As shown in

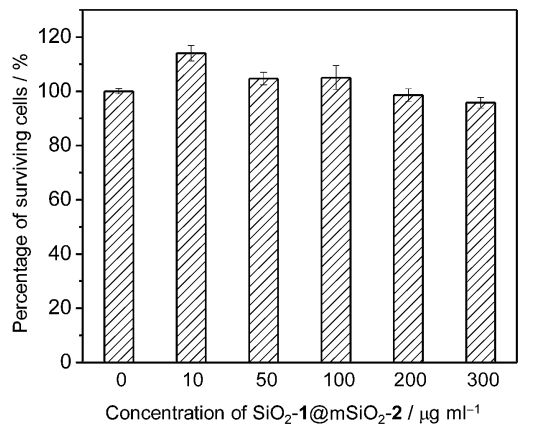

Fig. 5 Percentage of surviving RAW 264.7 cells after exposure to $\mathrm{SiO}_{2}-$ $1 \mathrm{amSiO}_{2}-2$ at $37{ }^{\circ} \mathrm{C}$ for $12 \mathrm{~h}$.

Fig. 6a, RAW 264.7 cells treated with $\mathrm{SiO}_{2}-1$ @mSiO ${ }_{2}-2$ $\left(120 \mu \mathrm{g} \mathrm{ml}^{-1}\right)$ for $3 \mathrm{~h}$ displayed intense blue phosphorescence and the red phosphorescence was hardly observed. Further incubation of the cells with $\mathrm{NaClO}(50 \mu \mathrm{M})$ for $1 \mathrm{~h}$ selectively and significantly enhanced the red phosphorescence. The overlaid images of the blue and red windows clearly showed that the dominance of the intracellular phosphorescence was shifted from the blue to the red window upon incubation with $\mathrm{ClO}^{-}$(Fig. 6a). The intensity ratio of the red window over the blue window, $I_{\text {red }} / I_{\text {blue }}$, was determined to increase from 0.16 to 1.6 upon $\mathrm{ClO}^{-}$oxidation of complex 2 to yield complex 2a, which is consistent with the results of the phosphorescence titration (Fig. 4a). Smaller $I_{\text {red }} / I_{\text {blue }}$ values were observed in both the absence and presence of $\mathrm{ClO}^{-}$compared to the results of the extracellular titration, probably due to nonspecific quenching of complexes $\mathbf{2} / \mathbf{2 a}$ that were localised on the outer layer of the nanoparticles in an intracellular environment. To demonstrate the resistance of the ratiometric detection to external influences, we repeated the intracellular sensing experiments with the following experimental changes: (1) the dose of $\mathrm{SiO}_{2}$ 1@ $\mathrm{mSiO}_{2}-2$ was increased to $180 \mu \mathrm{g} \mathrm{ml}{ }^{-1}$ or decreased to $60 \mu \mathrm{g}$ $\mathrm{ml}^{-1}$; (2) the incubation duration of $\mathrm{SiO}_{2}-\mathbf{1} @ \mathrm{mSiO}_{2}-2$ was increased to $6 \mathrm{~h}$; (3) the incubation temperature of $\mathrm{SiO}_{2}$ 1@ $\mathrm{mSiO}_{2}-2$ was reduced to $25{ }^{\circ} \mathrm{C}$; (4) the $405 \mathrm{~nm}$ laser power was randomly varied. In experiments (1)-(3) the intracellular amount of $\mathrm{SiO}_{2}-1 @ \mathrm{mSiO}_{2}-2$ was influenced, and in experiment (4) the amount of excited $\mathrm{SiO}_{2}-\mathbf{1} @ \mathrm{mSiO}_{2}-\mathbf{2}$ was affected randomly. The cell images are shown in Fig. S3. $\dagger$ The luminescence intensity recorded from the red window showed that the intensity-based detection of $\mathrm{ClO}^{-}$was disturbed by the external influences (Fig. 6b red). In contrast, with the signals from the blue window as an internal standard (Fig. $6 \mathrm{~b}$ blue), the $I_{\text {red }} / I_{\text {blue }}$ values were almost unaffected (Fig. $6 \mathrm{~b}$ green), demonstrating the strong resistance of the ratiometric detection toward external influences. Therefore, ratiometric sensors are more useful compared to luminescence turn-on or turn-off probes when used in a complex environment such as in intracellular and in vivo applications.

As RAW 264.7 cells are known to produce endogenous $\mathrm{ClO}^{-}$ when stimulated with lipopolysaccharide (LPS) and phorbol myristate acetate (PMA), ${ }^{5 e, 7 b, 8,16}$ the feasibility of utilizing $\mathrm{SiO}_{2^{-}}$ 1@ $\mathrm{mSiO}_{2}-2$ to detect endogenous $\mathrm{ClO}^{-}$was tested. The 
(a) $\lambda_{\mathrm{em}}=$
$480 \pm 20 \mathrm{~nm}$
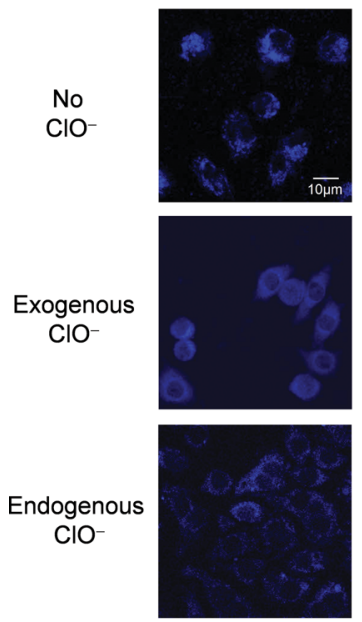

(b)

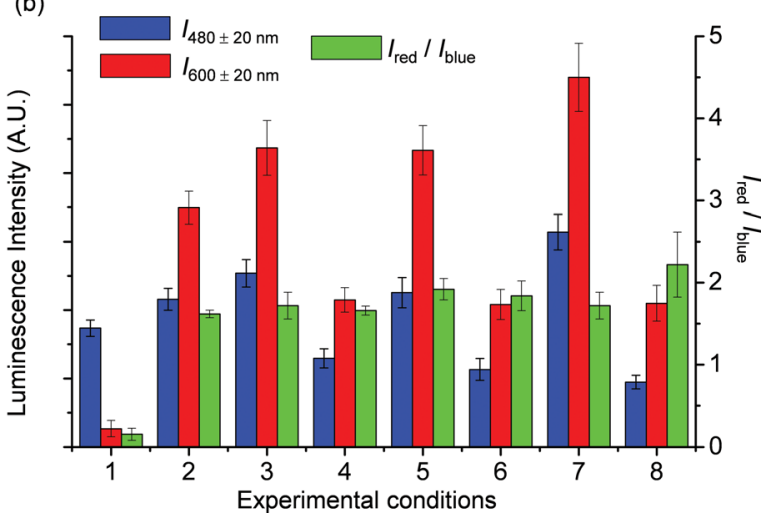

Fig. 6 (a) Luminescence images of RAW 264.7 cells treated with $\mathrm{SiO}_{2}-$ $1 \mathrm{amSiO}_{2}-2\left(120 \mu \mathrm{g} \mathrm{ml}^{-1}\right)$ for $3 \mathrm{~h}$ at $37^{\circ} \mathrm{C}$ (top), followed by incubation with $\mathrm{NaClO}(50 \mu \mathrm{M})$ for $1 \mathrm{~h}$ (middle), and RAW 264.7 cells stimulated with LPS and PMA, and incubated with $\mathrm{SiO}_{2}-1 \mathrm{amSiO}_{2}-2\left(120 \mu \mathrm{g} \mathrm{ml}^{-1}\right)$ for $2 \mathrm{~h}$ at $37^{\circ} \mathrm{C}$ (bottom). (b) Luminescence intensity of RAW 264.7 cells recorded from the blue window (blue) and the red window (red) and the intensity ratio $I_{\text {red }} / I_{\text {blue }}$ (green). Experimental conditions: RAW 264.7 cells were treated with $\mathrm{SiO}_{2}-1 \mathrm{amSiO}_{2}-2\left(120 \mu \mathrm{g} \mathrm{ml}^{-1}\right)$ for $3 \mathrm{~h}$ at $37^{\circ} \mathrm{C}$ without (1) and with (2) further incubation with $\mathrm{NaClO}(50 \mu \mathrm{M})$ for $1 \mathrm{~h}$; the concentration of $\mathrm{SiO}_{2}-1 \mathrm{amSiO}_{2}-2$ was increased to $180 \mu \mathrm{g}$ $\mathrm{ml}^{-1}$ (3) and decreased to $60 \mu \mathrm{g} \mathrm{ml}^{-1}$ (4); the incubation duration of $\mathrm{SiO}_{2}-1\left(\mathrm{amSiO}_{2}-2\right.$ was increased to $6 \mathrm{~h}$ (5); the incubation temperature of $\mathrm{SiO}_{2}-1 \mathrm{amSiO}_{2}-2$ was reduced to $25^{\circ} \mathrm{C}(6)$; the $405 \mathrm{~nm}$ laser power was randomly increased (7); and detection of endogenous $\mathrm{ClO}^{-}$was recorded (8).
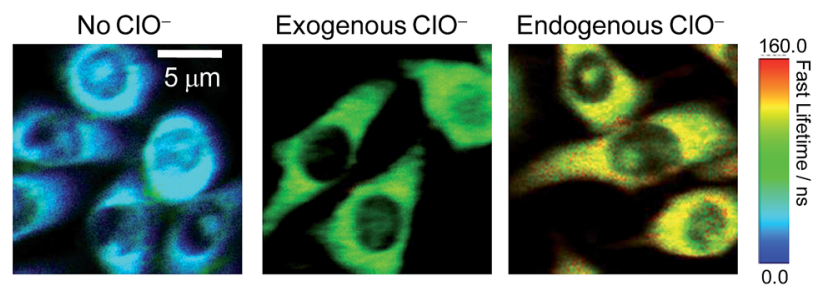

Fig. 7 PLIM images of RAW 264.7 cells treated with $\mathrm{SiO}_{2}-1 \mathrm{amSiO}_{2}-2$ $\left(120 \mu \mathrm{g} \mathrm{ml}^{-1}\right)$ for $2 \mathrm{~h}$ at $37^{\circ} \mathrm{C}$ (left), followed by treatment with $\mathrm{NaClO}$ $(50 \mu \mathrm{M})$ for $1 \mathrm{~h}$ (middle), and RAW 264.7 cells stimulated with LPS and PMA and incubated with $\mathrm{SiO}_{2}-1 \mathrm{amSiO}_{2}-2\left(120 \mu \mathrm{g} \mathrm{ml}^{-1}\right)$ for $2 \mathrm{~h}$ at $37^{\circ} \mathrm{C}$ (right). stimulated RAW 264.7 cells showed intense red luminescence after incubation with $\mathrm{SiO}_{2}-\mathbf{1} @ \mathrm{mSiO}_{2}-\mathbf{2}$ for $2 \mathrm{~h}$, with an $I_{\text {red }} / I_{\text {blue }}$ value of $2.2 \pm 0.4$ (Fig. 6). This ratio was larger than those obtained in the detection of exogenous $\mathrm{ClO}^{-}$. This might be because $\mathrm{SiO}_{2}-1 @ \mathrm{mSiO}_{2}-2$ was more ready to react with endogenous $\mathrm{ClO}^{-}$, since internalisation of $\mathrm{ClO}^{-}$into cells was not required. Interestingly, the overlaid images showed that the red and blue phosphorescence signals were well colocalised in the measurement of exogenous $\mathrm{ClO}^{-}$. However, they only partially overlapped in the detection of endogenous $\mathrm{ClO}^{-}$, indicating that the distribution of exogenous $\mathrm{ClO}^{-}$was not even inside the

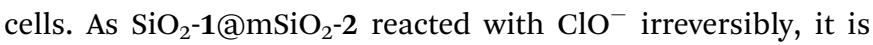
important to point out that the measured $I_{\text {red }} / I_{\text {blue }}$ value cannot be used to determine the average concentration of intracellular $\mathrm{ClO}^{-}$. However, the data can serve as an approximate indicator for intracellular $\mathrm{ClO}^{-}$generation.

\section{Photoluminescence lifetime imaging of intracellular $\mathrm{ClO}^{-}$}

The significant $\mathrm{ClO}^{-}$-induced lifetime elongation of the red phosphorescence of $\mathrm{SiO}_{2}-\mathbf{1} @ \mathrm{mSiO}_{2}-\mathbf{2}$ encouraged us to investigate the intracellular sensing behaviour of the nanoparticles via PLIM. RAW 264.7 cells treated with $\mathrm{SiO}_{2}-1 @ \mathrm{mSiO}_{2}-2$ $\left(120 \mu \mathrm{g} \mathrm{ml}{ }^{-1}\right)$ for $2 \mathrm{~h}$ at $37^{\circ} \mathrm{C}$ showed an average luminescence lifetime of about $31 \mathrm{~ns}$ (Fig. 7). Further incubation with NaClO $(50 \mu \mathrm{M})$ for $1 \mathrm{~h}$ elongated this value to about $91 \mathrm{~ns}$ due to the oxidation of complex 2 to complex $2 \mathrm{a}$. When the cells were stimulated with LPS and PMA, $\mathrm{SiO}_{2}-\mathbf{1} @ \mathrm{mSiO}_{2}-2$ displayed a longer lifetime of about $116 \mathrm{~ns}$ without $\mathrm{NaClO}$ treatment to the cells, which was consistent with the results of the ratiometric detections, that endogenous $\mathrm{ClO}^{-}$led to a higher degree of conversion of complex 2 to complex $2 \mathrm{a}$ compared to exogenous $\mathrm{ClO}^{-}$. All these results indicated that $\mathrm{SiO}_{2}-1 @ \mathrm{mSiO}_{2}-2$ can be used to detect both exogenous and endogenous $\mathrm{ClO}^{-}$via PLIM with high sensitivity.

\section{Conclusions}

In summary, we have described a new design strategy to construct a ratiometric sensing system based on core-shell structured silica nanoparticles, and prepared a phosphorescent ratiometric probe for $\mathrm{ClO}^{-}$by incorporation of two iridium(III) complexes into the nanoparticles. The utilisation of this probe to detect intracellular exogenous and endogenous $\mathrm{ClO}^{-}$has been demonstrated via ratiometric imaging and PLIM. Compared to intensity-based sensing and imaging, both ratiometric and lifetime-based detections are less affected by probe concentration and laser source power. Additionally, in PLIM, the phosphorescence signals are distinguishable from shortlived background interference. Importantly, the design strategy for ratiometric and lifetime-based sensors in this work is not limited to hypochlorite sensing; the incorporation of responsive compounds as reporters and insensitive compounds as internal standards into the core-shell structured nanoparticles will lead to new ratiometric sensors for specific analytes. The utilisation of long-lived luminescent compounds will enable lifetimebased measurements in intracellular applications. 


\section{Acknowledgements}

The financial support from the National Basic Research Program of China (2012CB933301), National Natural Science Foundation of China (21171098), Program for New Century Excellent Talents in University (NCET-12-0740), the Ministry of Education of China (IRT1148 and 20133223110006), Natural Science Foundation of Jiangsu Province of China (BK20130038) and Priority Academic Program Development of Jiangsu Higher Education Institutions is acknowledged.

\section{Notes and references}

1 M. Deborde and U. von Gunten, Water Res., 2008, 42, 13-51. 2 (a) T. Ozben, J. Pharm. Sci., 2007, 96, 2181-2196; (b) C. C. Winterbourn, Nat. Chem. Biol., 2008, 4, 278-286; (c) Z. M. Prokopowicz, F. Arce, R. Biedroń, C. L. Chiang, M. Ciszek, D. R. Katz, M. Nowakowska, S. Zapotoczny, J. Marcinkiewicz and B. M. Chain, J. Immunol., 2010, 184, 824-835.

3 (a) J. E. Harrison and J. Shultz, J. Biol. Chem., 1976, 251, 1371-1374; (b) D. I. Pattison and M. J. Davies, Biochemistry, 2006, 45, 8152-8162; (c) S. E. Gomez-Mejiba, Z. Zhai, M. S. Gimenez, M. T. Ashby, J. Chilakapati, K. Kitchin, R. P. Mason and D. C. Ramirez, J. Biol. Chem., 2010, 285, 20062-20071.

4 R. A. Roberts, D. L. Laskin, C. V. Smith, F. M. Robertson, E. M. Allen, J. A. Doorn and W. Slikker, Toxicol. Sci., 2009, 112, 4-16.

5 (a) S. Kenmoku, Y. Urano, H. Kojima and T. Nagano, J. Am. Chem. Soc., 2007, 129, 7313-7318; (b) Y.-K. Yang, H. J. Cho, J. Lee, I. Shin and J. Tae, Org. Lett., 2009, 11, 859-861; (c) T.-I. Kim, S. Park, Y. Choi and Y. Kim, Chem.-Asian J., 2011, 6, 1358-1361; (d) X. Cheng, H. Jia, T. Long, J. Feng, J. Qin and Z. Li, Chem. Commun., 2011, 47, 11978-11980; (e) Y. Koide, Y. Urano, K. Hanaoka, T. Terai and T. Nagano, J. Am. Chem. Soc., 2011, 133, 5680-5682; (f) Y. Zhou, J.-Y. Li, K.-H. Chu, K. Liu, C. Yao and J.-Y. Li, Chem. Commun., 2012, 48, 4677-4679; (g) X. Jin, L. Hao, Y. Hu, M. She, Y. Shi, M. Obstb, J. Li and Z. Shi, Sens. Actuators, B, 2013, 186, 56-60; (h) Q. Xu, K.-A. Lee, S. Lee, K. M. Lee, W.-J. Lee and J. Yoon, J. Am. Chem. Soc., 2013, 135, 99449949; (i) X. Wu, Z. Li, L. Yang, J. Han and S. Han, Chem. Sci., 2013, 4, 460-467; (j) M. Sun, H. Yu, H. Zhu, F. Ma, S. Zhang, D. Huang and S. Wang, Anal. Chem., 2014, 86, 671-677.

6 P. Panizzi, M. Nahrendorf, M. Wildgruber, P. Waterman, J.-L. Figueiredo, E. Aikawa, J. McCarthy, R. Weissleder and S. A. Hilderbrand, J. Am. Chem. Soc., 2009, 131, 15739-15744.

7 (a) N. Zhao, Y.-H. Wu, R.-M. Wang, L.-X. Shi and Z.-N. Chen, Analyst, 2011, 136, 2277-2282; (b) R. Zhang, Z. Ye, B. Song, Z. Dai, X. An and J. Yuan, Inorg. Chem., 2013, 52, 1032510331; (c) K. Chen, J. W. Bats and M. Schmittel, Inorg. Chem., 2013, 52, 12863-12865.

8 Y. Xiao, R. Zhang, Z. Ye, Z. Dai, H. An and J. Yuan, Anal. Chem., 2012, 84, 10785-10792.
9 (a) K. K.-W. Lo, K. Y. Zhang, S.-K. Leung and M.-C. Tang, Angew. Chem., Int. Ed., 2008, 47, 2213-2216; (b) J. Liu, Y. Liu, Q. Liu, C. Li, L. Sun and F. Li, J. Am. Chem. Soc., 2011, 133, 15276-15279; (c) T. Yoshihara, Y. Yamaguchi, M. Hosaka, T. Takeuchi and S. Tobita, Angew. Chem., Int. Ed., 2012, 51, 4148-4151; (d) S. Gehrig, M. A. Mall and C. Schultz, Angew. Chem., Int. Ed., 2012, 51, 6258-6261; (e) W. Shi, X. Li and H. Ma, Angew. Chem., Int. Ed., 2012, 51, 6432-6435; $(f)$ Y. Chen, C. Zhu, Z. Yang, J. Chen, Y. He, Y. Jiao, W. He, L. Qiu, J. Cen and Z. Guo, Angew. Chem., Int. Ed., 2013, 52, 1688-1691; (g) X. Wang, J. Sun, W. Zhang, X. Ma, J. Lv and B. Tang, Chem. Sci., 2013, 4, 2551-2556; (h) D. Meng, S. Yang, D. Sun, Y. Zeng, J. Sun, Y. Li, S. Yan, Y. Huang, C. W. Bielawski and J. Geng, Chem. Sci., 2014, 5, 3130-3134.

10 (a) R. G. Chaudhuri and S. Paria, Chem. Rev., 2012, 112, 2373-2433; (b) K. E. Sapsford, W. R. Algar, L. Berti, K. B. Gemmill, B. J. Casey, E. Oh, M. H. Stewart and I. L. Medintz, Chem. Rev., 2013, 113, 1904-2074; (c) V. Valtchev and L. Tosheva, Chem. Rev., 2013, 113, 67346760; (d) X. Wu, S. Chang, X. Sun, Z. Guo, Y. Li, J. Tang, Y. Shen, J. Shi, H. Tian and W. Zhu, Chem. Sci., 2013, 4, 1221-1228; (e) X. Wu and W. Zhu, Chem. Soc. Rev., 2014, DOI: $10.1039 / \mathrm{c} 4 \operatorname{cs} 00152 \mathrm{~d}$.

11 (a) Q. Zhao, L. Li, F. Li, M. Yu, Z. Liu, T. Yi and C. Huang, Chem. Commun., 2008, 685-687; (b) M. Yu, Q. Zhao, L. Shi, F. Li, Z. Zhou, H. Yang, T. Yi and C. Huang, Chem. Commun., 2008, 2115-2117; (c) Q. Zhao, F. Li and C. Huang, Chem. Soc. Rev., 2010, 39, 3007-3030; (d) C. Li, M. Yu, Y. Sun, Y. Wu, C. Huang and F. Li, J. Am. Chem. Soc., 2011, 133, 11231-11239; (e) Q. Zhao, C. Huang and F. Li, Chem. Soc. Rev., 2011, 40, 2508-2524; (f) Q. Liu, T. Yang, W. Feng and F. Li, J. Am. Chem. Soc., 2012, 134, 5390-5397; (g) K. K.-W. Lo, A. W.-T. Choi and W. H.-T. Law, Dalton Trans., 2012, 41, 6021-6047; $(h)$ K. Y. Zhang and K. K.-W. Lo, in Comprehensive Inorganic Chemistry II, ed. J. Reedijk and K. Poeppelmeier, Elsevier, Oxford, 2013, vol. 8, pp. 657-732; (i) Q. Liu, B. Yin, T. Yang, Y. Yang, Z. Shen, P. Yao and F. Li, J. Am. Chem. Soc., 2013, 135, 5029-5037; (j) K. Y. Zhang and K. K.-W. Lo, in Inorganic Chemical Biology: Principles, Techniques and Applications, ed. G. Gasser, John Wiley \& Sons, Ltd, Chichester, UK, 2014, pp. 99-147.

12 (a) Y. You, S. Lee, T. Kim, K. Ohkubo, W.-S. Chae, S. Fukuzumi, G.-J. Jhon, W. Nam and S. J. Lippard, J. Am. Chem. Soc., 2011, 133, 18328-18342; (b) E. Baggaley, J. A. Weinstein and J. A. G. Williams, Coord. Chem. Rev., 2012, 256, 1762-1785; (c) H. Woo, S. Cho, Y. Han, W.-S. Chae, D.-R. Ahn, Y. You and W. Nam, J. Am. Chem. Soc., 2013, 135, 4771-4787; (d) C. Shi, H. Sun, X. Tang, W. Lv, H. Yan, Q. Zhao, J. Wang and W. Huang, Angew. Chem., Int. Ed., 2013, 52, 13434-13438; (e) H. Shi, H. Sun, H. Yang, S. Liu, G. Jenkins, W. Feng, F. Li, Q. Zhao, B. Liu and W. Huang, Adv. Funct. Mater., 2013, 23, 3268-3276; (f) Y. Ma, S. Liu, H. Yang, Y. Wu, H. Sun, J. Wang, Q. Zhao, F. Li and W. Huang, J. Mater. Chem. B, 2013, 1, 319-329; (g) W. Xu, X. Zhao, W. Lv, H. Yang, S. Liu, H. Liang, Z. Tu, 
H. Xu, W. Qiao, Q. Zhao and W. Huang, Adv. Healthcare Mater., 2014, 3, 658-669.

13 S.-H. Wu, C.-Y. Mou and H.-P. Lin, Chem. Soc. Rev., 2013, 42, 3862-3875.

14 (a) S.-W. Li, Y.-M. Cheng, Y.-S. Yeh, C.-C. Hsu, P.-T. Chou, S.-M. Peng, G.-H. Lee, Y.-L. Tung, P.-C. Wu, Y. Chi, F.-I. Wu and C.-F. Shu, Chem.-Eur. J., 2005, 11, 6347-6357; (b) K. K.-W. Lo, K. Y. Zhang, C.-K. Chung and K. Y. Kwok, Chem.-Eur. J., 2007, 13, 7110-7120.

15 T. Mosmann, J. Immunol. Methods, 1983, 65, 55-63.

16 R. Wippel, M. Rehn, A. C. F. Gorren, K. Schmidt and B. Mayer, Biochem. Pharmacol., 2004, 67, 1285-1295. 